Sharif University of Technology
Scientia Iranica
SCIENTIA
TRANactions A: Civil Engineering
IRItp://scientiairanica.sharif.edu

\title{
Behavior and design of fin walls at the periphery of strong core wall structure in high-rise buildings
}

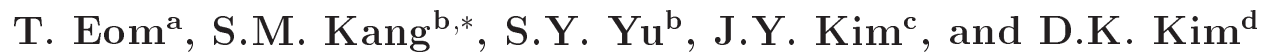 \\ a. Department of Architectural Engineering, Dankook University, 152 Jukjeon-ro, Gyeonggi-do, Korea, 448-701. \\ b. Department of Architectural Engineering, Chungbuk National University, Chungdae-ro 1, Seowon-Gu, Cheongju, Chungbuk, \\ Korea, 361-763. \\ c. Department of Architectural Engineering, Kwangwoon University, Nowon-gu, Seoul, Korea, 139-701. \\ d. Department of Architectural Engineering, Cheongju University, Daeseong-ro 298, Cheongwon-gu, Cheongju, Chungbuk, Korea.
}

Received 19 October 2016; received in revised form 7 February 2017; accepted 18 April 2017

\section{KEYWORDS}

High-rise RC

structural walls;

Fin walls;

Alternative design;

Inelastic analysis;

Coupling beam;

High-rise building

design.

\begin{abstract}
In high-rise buildings, Reinforced Concrete (RC) structural walls frequently resist lateral loads, such as wind and seismic loads. Behavior and design of fin walls at the periphery of strong core wall structure in high-rise buildings have not been analyzed seriously despite their structural importance. Using elastic design/analysis methodologies for the design of high-rise RC fin walls, it is shown that elicited reinforcement ratios are too high; thus, the economic feasibility and constructability become worse and the ductile failure mode cannot be assured. In the present study, the current design process of these fin walls is investigated by analyzing their structural behavior. According to the investigation of the current design and elicited results, high-rise RC fin walls are coupled by beams, although they are located on another line and apart from each other, which is main cause of high reinforcement in high-rise RC fin walls. In the present study, a literature review has been conducted to recommend the alternative design method for high-rise RC fin walls under lateral loads, and inelastic analysis has been performed to verify the design method.
\end{abstract}

(C) 2018 Sharif University of Technology. All rights reserved.

\section{Introduction}

In high-rise buildings, Reinforced Concrete (RC) structural walls frequently resist lateral loads, such as wind and seismic loads [1-3]. Since RC structural walls have large stiffness and strength, they can control deformation and efficiently assure the strength of the building structure. In the structural design of $\mathrm{RC}$ building structures, the RC structural walls are de-

*. Corresponding author. Tel.: +82-10-9208-4116

E-mail addresses: tseom@dankook.ac.kr (T.Eom);

kangsm@cbnu.ac.kr (S.M. Kang);

dbtmddbs3414@naver.com (S.Y.Yu); kimjyo@kw.ac.kr

(J.Y.Kim); dkkim@senkuzo.com (D.K.Kim)

doi: $10.24200 /$ sci. 2017.4224 signed as independent single walls (isolated walls) or coupled walls connected by connecting beams, which are located closely on a straight line. However, in the high-rise RC building structures, in many cases, the structural RC walls are located on another line and apart from each other and are designed generally as independent single walls (isolated walls) regardless of their structural behavior.

Figure 1 shows a typical example of a structural system for a 35-story residential building. As shown in Figure 1, the gravity load is resisted by the RC flat plate slab and the RC column. Currently, RC flat plates are used frequently as a slab system since they can decrease the floor height and construction time and increase space utilization and constructability. As shown in Figure 1(b), RC structural walls frequently 


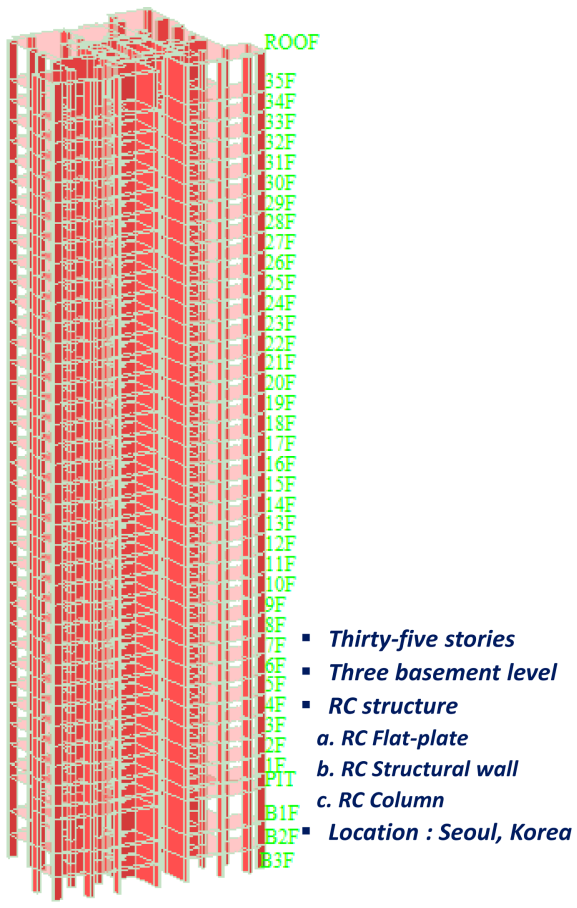

(a) 35 stories residential building

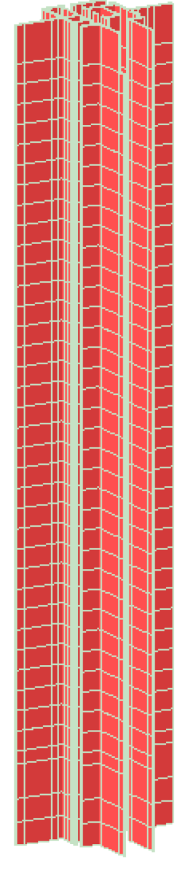

- RC Structural wall

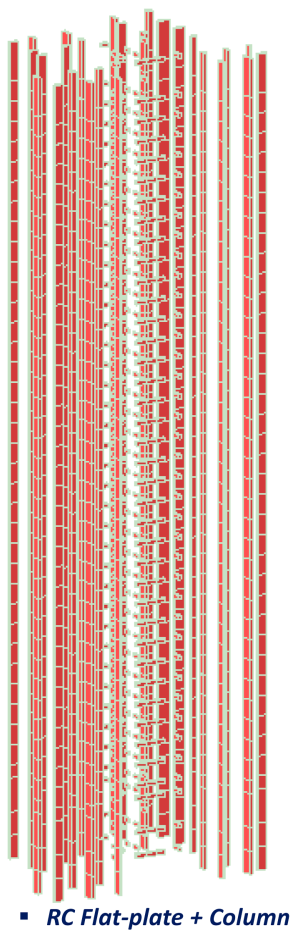

late + Column

Figure 1. Typical example of structural system for high-rise residential buildings.

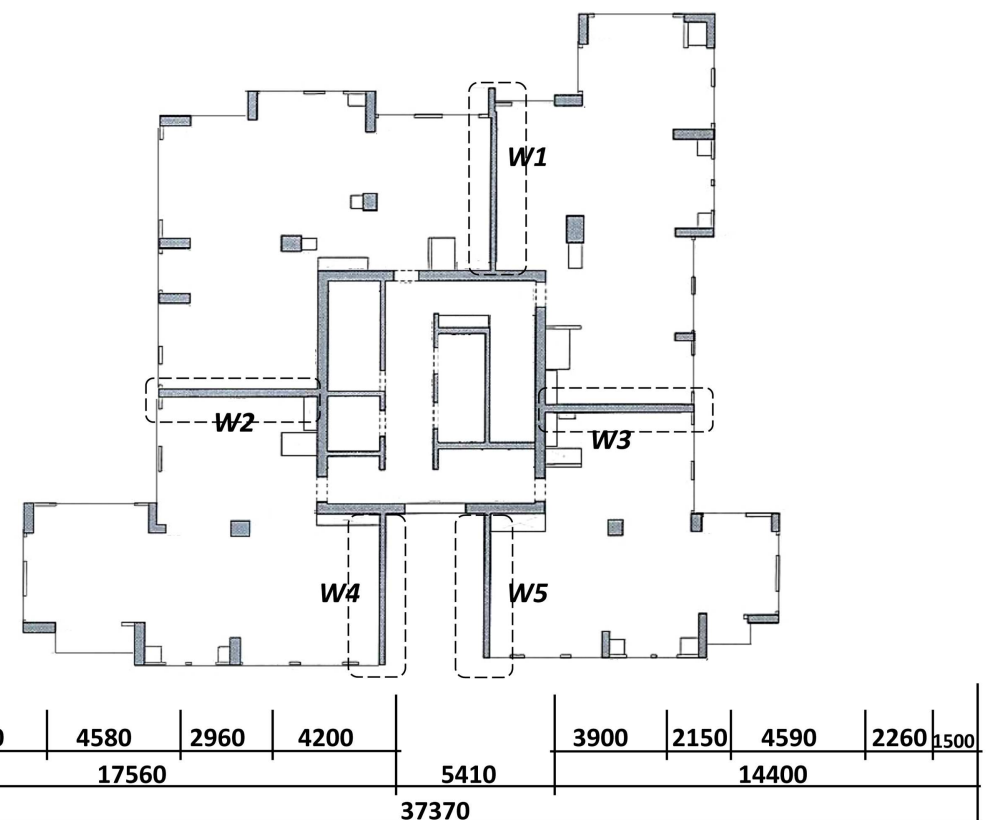

Figure 2. Structural plan of an example building for the case study.

resist the lateral load since they have large stiffness and strength owing to their long length. Figure 2 shows the building plan drawn in Figure 1. As mentioned above, RC structural walls are located in the center of the plan to resist the lateral load. In the plan, some $\mathrm{RC}$ structural walls are extended from the center to the boundary of the plan, called as "Fin walls" (Fin walls indicate planar walls such as W1 $\sim$ W5 installed along the perimeter of the rectangular core wall structure, as shown in Figure 2). These RC structural walls, fin walls, are used frequently to divide the space for architectural design and to control the lateral deflection of the high-rise building, because they can enlarge the moment inertia of the building system effectively. Generally, they are located on another line and apart from each other and are designed as independent single 
Table 1. Reinforcement detail of RC structural walls.

\begin{tabular}{|c|c|c|c|c|}
\hline \multicolumn{5}{|c|}{ Wall list (at floor B3) } \\
\hline Wall & Story & Thickness (mm) & Vertical reinforcement & Horizontal reinforcement \\
\hline W1 & B3F-B2F & 300 & $\mathrm{D} 22$ at $100(2.58 \%)$ & D10 at 150 \\
\hline $\mathrm{W} 2$ & B3F-B1F & 300 & D25 at $100(3.38 \%)$ & D13 at 200 \\
\hline W3 & B3F-B1F & 300 & $\mathrm{D} 22$ at $100(2.58 \%)$ & D10 at 130 \\
\hline W4 & $\mathrm{B} 3 \mathrm{~F}-\mathrm{B} 2 \mathrm{~F}$ & 300 & D13 at $150(0.59 \%)$ & D10 at 190 \\
\hline W5 & $\mathrm{B} 3 \mathrm{~F}-\mathrm{B} 2 \mathrm{~F}$ & 300 & D16 at $125(1.07 \%)$ & D10 at 190 \\
\hline
\end{tabular}

walls regardless of their structural behavior. However, as shown in Table 1, the reinforcement ratio of these $\mathrm{RC}$ fin walls on floor B3 ranges from $0.59 \%$ to $3.38 \%$. In accordance with the current structural design code, such as ACI 318-14 [4], the reinforcement ratio of the $\mathrm{RC}$ structural walls is limited to $1 \%$ when they are not enclosed by transverse ties. Therefore, some of these structural walls violate the requirement prescribed by the design code if they are not enclosed by transverse ties. Furthermore, in the cases where the reinforcement ratio is more than $1 \%$, its value is considered to be too high to assure economic feasibility and constructability. Moreover, the application of the transverse ties to the RC structural walls with more than $1 \%$ reinforcement ratio decreases constructability significantly. In addition, if the flexural reinforcement in high-rise $\mathrm{RC}$ structural walls is placed excessively regardless of their structural behavior, it may lead to unexpected brittle shear failure of high-rise RC structural walls. In this study, structural behavior of fin walls installed along the periphery of strong core wall structure in high-rise buildings is studied. Elastic analysis of a 35-story highrise building with core walls and fin walls is carried out, and the design loads acting on each fin wall, such as axial load and bending moment, are investigated. Further, flexure-compression design of the fin walls is carried out, and the reason why the design results (i.e., reinforcement amounts) significantly differ among the fin walls is then discussed in detail. Based on these investigations, their alternative design method is investigated based on literature review. Further, this alternative design method is verified using the latest structural analysis method for RC structural wall system.

\section{Investigation of the results of the current design}

As mentioned above, the values of the flexural reinforcement ratios of $\mathrm{RC}$ fin walls that extend from the center to the boundary of the plan are too high (Table 1). In this study, applied loads and strengths of walls W2 and W3 on floor B3 that yielded the largest flexural reinforcement ratio are investigated through elastic analyses using the Midas Gen program [5]. Recently, new theories on the structural analysis of beams and plates have been developed to improve accuracy and convergence. Bourada et al. (2015) developed a simple and refined trigonometric higherorder beam theory for functionally graded beams [6]. Tounsi et al. (2016) proposed a new 3-unknown nonpolynomial plate theory for functionally graded sandwich plates [7]. Hebali et al. (2014) developed a new quasi-3D hyperbolic shear deformation theory for functionally graded plates [8]. Bennoun et al. (2016) devised a novel five-variable refined plate theory for functionally graded sandwich plates [9]. Ait Yahia et al. (2015) investigated wave propagation in functionally graded plates [10]. Belabed et al. (2014) invented an efficient and simple higher order shear and normal deformation theory [11]. Houari et al. (2016) developed a new simple three-unknown sinusoidal shear deformation theory for functionally graded plates [12]. Mahi et al. (2015) proposed a new hyperbolic shear deformation theory for functionally graded, sandwich and laminated composite plates [13]. However, in this study, to investigate the overall behavior of a highrise $\mathrm{RC}$ structural wall system in an overall framework and to use commercial program, the Midas Gen program [5], which is FEM program, was used using the conventional beam theory.

Figure 3 shows the P-M curves' relationship of walls W2 and W3 on floor B3 as the strength capacity of these wall sections. Moreover, round dots in Figure 3(b) and (c) represent the applied axial load and moment according to load combinations. As shown in Figure 3(b) and (c), the flexural reinforcement ratios of walls W2 and W3 were determined based on the load case, including the wind loads (W1, W2), which is a common phenomenon in high-rise buildings. Therefore, walls W2 and W3 are designed to resist the wind load as the critical lateral load. In Figure 3(b) and (c), the axial load is proportional to the moment load. This is not a typical feature for isolated RC structural walls in general. In Figure 4, the axial load applied to walls W2 and W3 is investigated according to the load case.

As shown in this figure, the axial load of wall $\mathrm{W} 2$ is inversely proportional to that of wall W3. This 


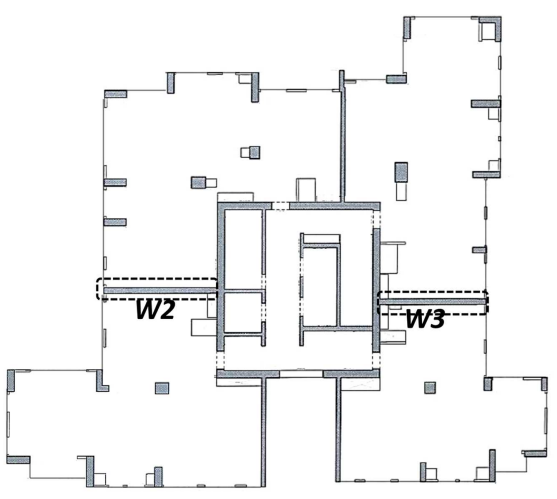

(a) Building plan

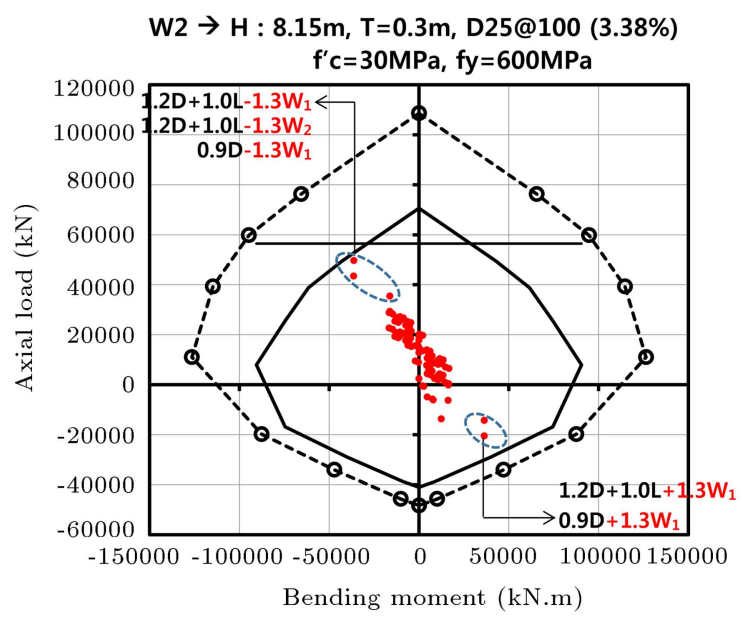

(b) Applied load and capacity of wall (W2)

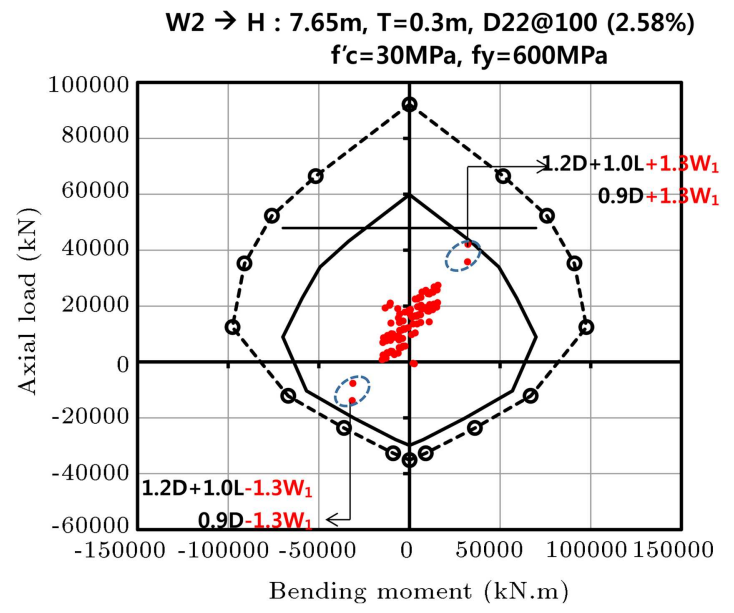

(c) Applied load and capacity of wall (W3)

Figure 3. Applied load and strength of walls W2 and W3 on floor B3.

means that walls W2 and W3 are coupled with each other by the coupling beams, although the two walls are physically located far apart from each other and on another line. As shown in Figure 4(b), walls W2 and W3 are connected by center walls and coupling beams. Since center walls have relatively large stiffness, the coupling level of walls W2 and W3 may be determined by the stiffness of the coupling beams. To verify this coupling behavior of walls W2 and W3, their strain distribution under the wind load was investigated according to the stiffness of the coupling beams (Figure 5). In the present study, strain distribution of coupled walls under the wind load was calculated by cross-sectional analysis. The cross-sectional analysis was based on the plane hypothesis and the equilibrium condition. The stress-strain relation for the concrete and steel rebars was assumed to be linear because, in the majority of cases, the maximum concrete stress was less than half of the concrete strength and the maximum tensile stress of steel rebar was much less than the yield stress. As shown in Figure 5, the strain distribution of walls W2 and W3 with stronger coupling beams under the wind load shows an increased linearity in the distribution of strain. This means that as the stiffness of the coupling beams becomes large, walls W2 and W3 behave as one unified wall. Therefore, walls W2 and W3 are coupled by the coupling beams, although they are located far apart with respect to each other and on another line, and the stiffness of the coupling beams is a key factor that determines the coupling level.

As shown in Figure 6(a), when the walls are coupled by coupling beams, these beams experience large deformation under lateral loads owing to the geometric shape of beams and walls. Because of this large deformation elicited under a lateral load, large shear forces occur in coupling beams. Correspondingly, these forces are then transferred to the coupled walls as an axial load [1]. In the case of high-rise buildings, the number of coupling beams is very large and the axial load that is transferred to the coupled walls is also large. As shown in Figure 6(b), when the wind 


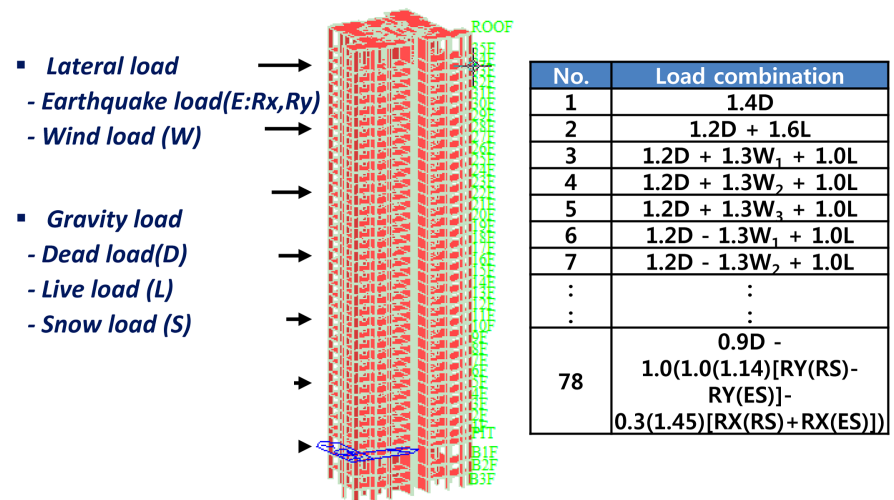

(a) Applied load and load combination

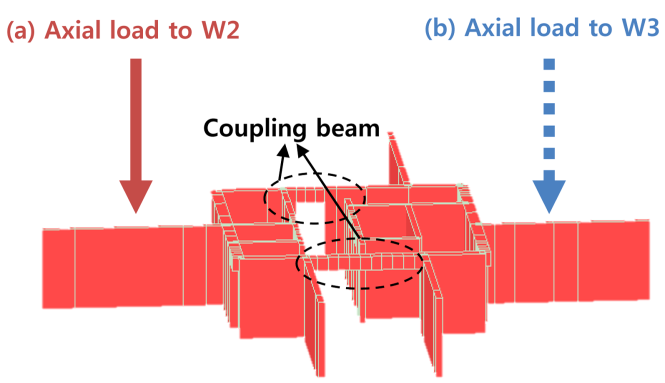

(b) Axial load applied to walls W2 and W3 at B3

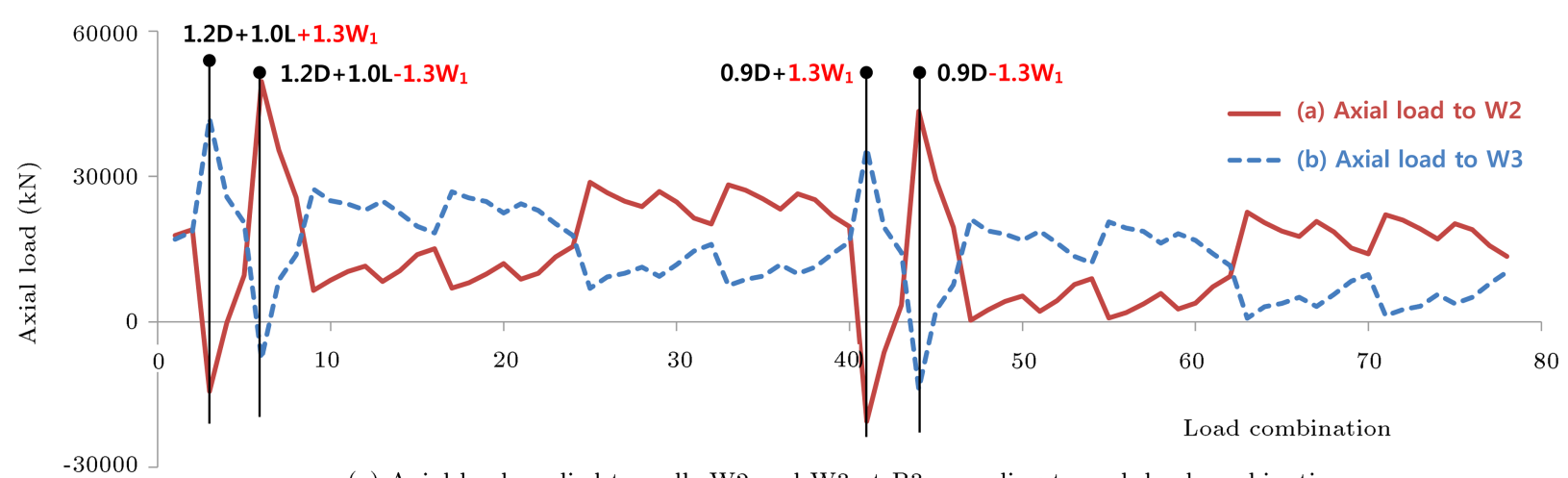

(c) Axial load applied to walls W2 and W3 at B3 according to each load combination

Figure 4. Axial load applied to walls W2 and W3 on floor B3 according to each load combination.

load is applied from the left to the right direction, the additional axial tensile load owing to the coupling beams is applied to wall W2, and the additional axial compressive load exerted by the coupling beams is applied to wall W3. As shown in Figure 6(c), when an additional axial tensile load is applied to $\mathrm{RC}$ structural walls, the moment capacity of these walls decreases and additional flexural reinforcement is required to resist the applied moment load. As shown in Figure 6(d), sometimes, when the additional axial compressive load that is applied is too high, the strength reduction factor for the structural RC walls would decrease. Therefore, in this case, additional flexural reinforcement or high-strength concrete should be used. Accordingly, the high flexural reinforcement ratio of the walls (extending from the center to the boundary of the plan) is caused by the additional axial load from the coupling of the beams. Moreover, these additional axial loads are relatively very high in value due to the large deformation of the coupling beams, as shown in Figure 6(a).

However, the additional axial load from the coupling beam, which is calculated as part of the elastic analysis, is larger than the value elicited from the actual behavior since the strength of the coupling beam is limited by the actual details of the beams $[1,14]$. Therefore, regarding the actual behavior of the coupled wall system can lead to a proposition of a reasonable design of these fin walls.

\section{Actual behavior and reasonable design of coupled fin walls}

To investigate the actual behavior of the coupled wall system, a literature review and an inelastic analysis were performed. According to Paulay and Priestley [1], the strength of a coupled wall system under lateral load can be determined by controlling the strength of individual walls as indicated below:

$$
M=M_{1}+M_{2}+l_{s} \times T
$$

where $M$ is the strength of the coupled wall system, $M_{1}\left(M_{2}\right)$ is the strength of the individual wall with additional axial tensile (compressive) load, $T$ is the axial load caused by the coupling beams, and $l_{s}$ is the length between the centroids of the coupled walls (See Figure 7 ). In the coupled wall system, the shear force generated by the coupling beams is transferred to the axial load of the wall. Generally, as shown in Figure 7, the shear force $(V)$ generated by the coupling beams is limited by the moment strength of coupling beams $\left(M_{b, i}\right)$, because the beams are designed to yield prior to failure by shear. Therefore, the axial load in the wall base $(T)$ can be calculated by summating the shear 


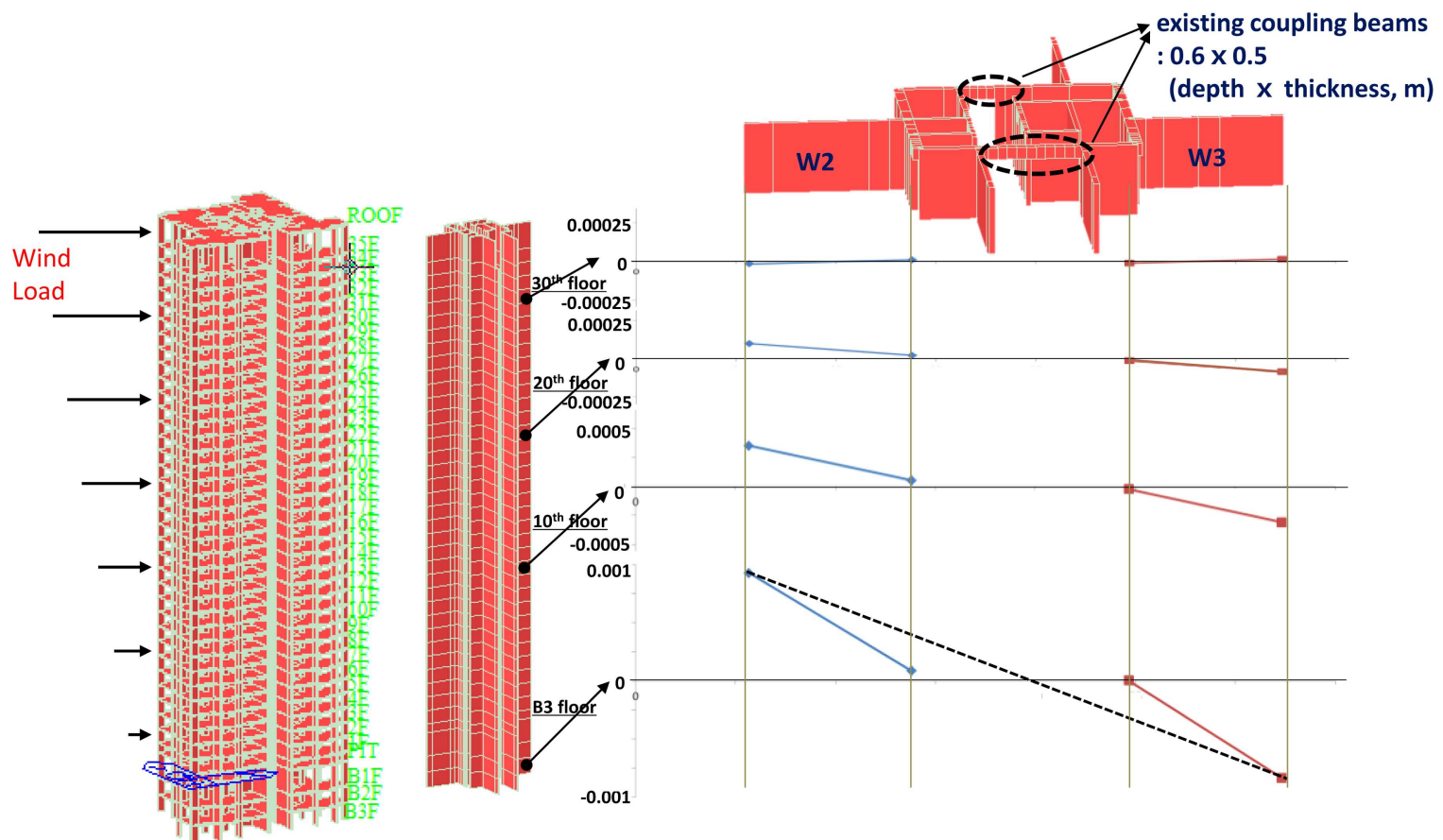

(a) Strain distribution of W2 and W3 with existing coupling beams under the wind load

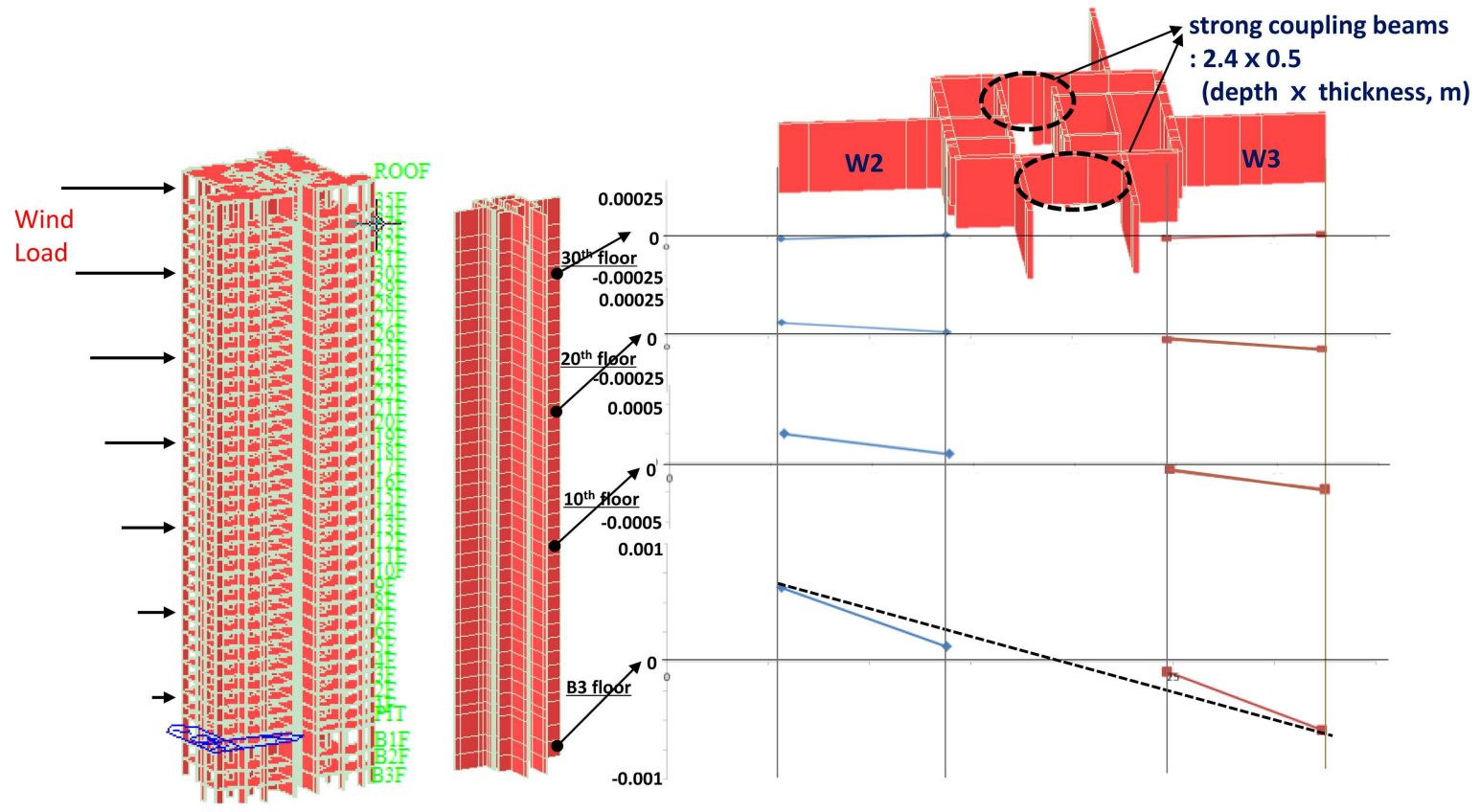

(b) Strain distribution of W2 and W3 with stronger coupling beams under the wind load

Figure 5. Strain distribution of walls W2 and W3 under the wind load according to the stiffness of the coupling beam.

force of the coupling beams at each story as follows [1]:

$$
T=\sum_{i=1}^{n} M_{b, i} / 2 l_{b}
$$

where $M_{b, i}$ is the moment strength of the coupling beams, $l_{b}$ is the beam length, and $n$ is the number of beam.
Therefore, the axial load transferred to the walls can be determined from the strength of the coupling beams. According to Paulay and Priestley [1], Paulay [14,15], and Santhakumar [16], the moment loading of an individual wall in a coupled wall system can be redistributed by maintaining the strength of the system (Eq. (1)). Therefore, using this design concept, the reinforcement ratio of the wall with an additional 


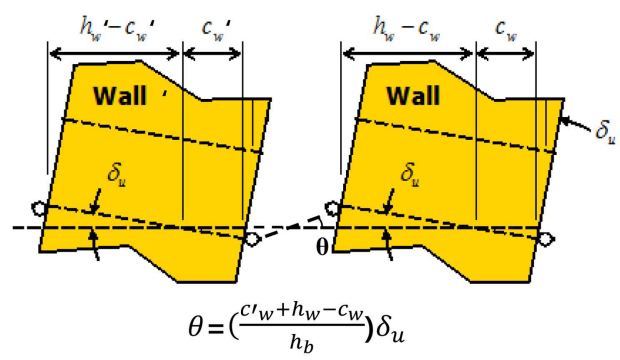

(a) Deformation of coupling beam

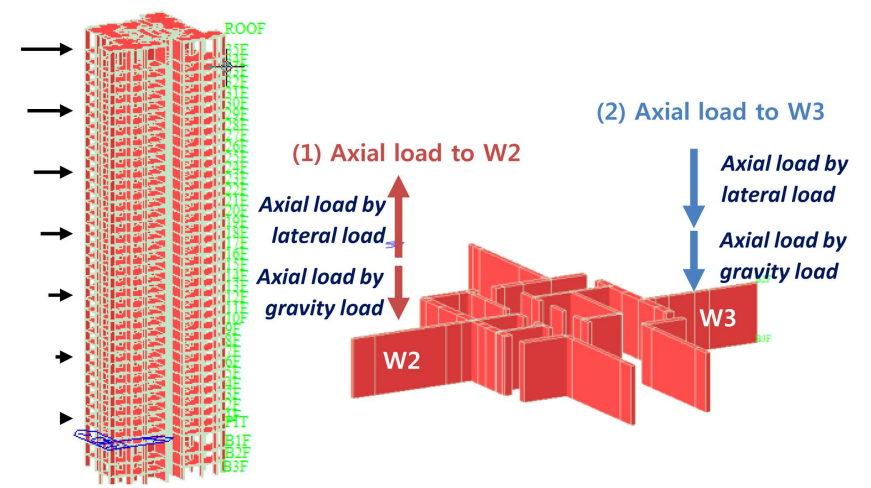

(b) Axial load applied to wall W2 and W3 at B3

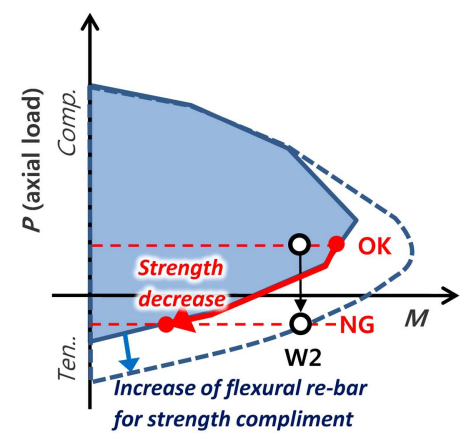

(c) Flexural rebar increase of wall with tensional load
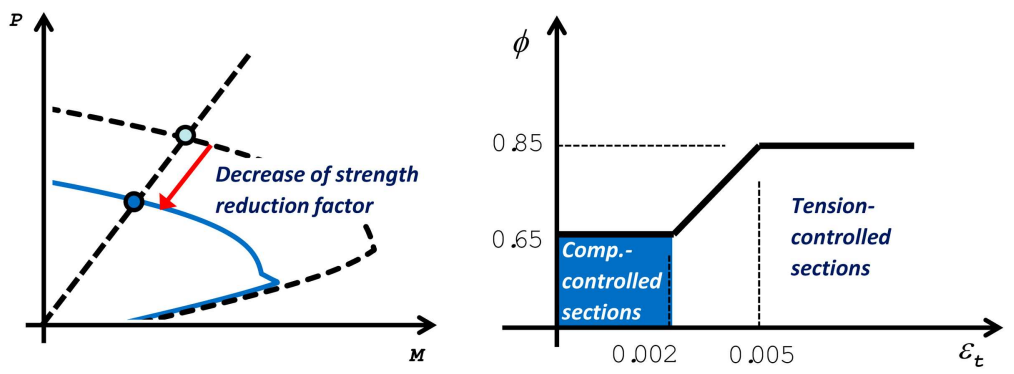

(d) Decrease of strength reduction factor of wall with compressive load

Figure 6. Increase of flexural reinforcement of coupled walls owing to additional axial loading.

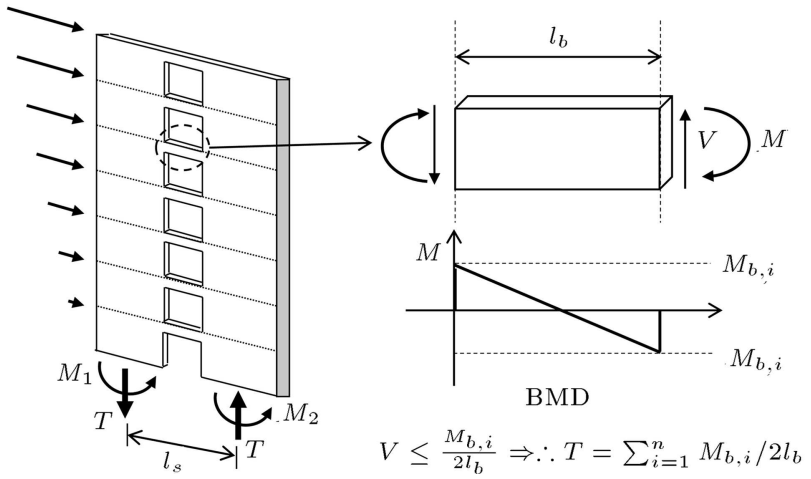

Figure 7. Strength of coupled wall system [1].

axial tensile load can be decreased by sending its moment load to the wall with an additional axial compressive load [1]. Correspondingly, the moment strength capacity of the wall is enlarged owing to the additional axial compressive load. In the present study, in order to verify this moment redistribution method for the coupled wall system and investigate its actual behavior, inelastic analysis is performed.

According to Kim et al. [17] and Park and Eom [18], the ultimate behavior of a coupled wall system can be accurately simulated by the Longitudinaland-Diagonal-Line-Element-Model (LDLEM) method. The LDLEM method has excellent stability for numerical analysis of structural wall systems, because it consists of simple trusses as a macro model as shown in Figure 8. Therefore, in this study, the LDLEM method was adopted for the inelastic analysis of a coupled wall system consisting of a number of structural members.

In the LDLEM method, the unit wall between the adjacent floors can be simulated using a simple longitudinal and diagonal truss model (see Figure 8). The diagonal truss was used to represent the shear resisting element, and the diagonal truss angle $\left(\theta_{c}\right)$ was defined to be the diagonal crack angle in the web of the $\mathrm{RC}$ wall. The diagonal crack angle could be calculated using the modified compression field theory proposed by Vecchio and Collins [19]. Moreover, according to Kim et al. [17], the diagonal truss angle could be simplified to $45^{\circ}$ for practical analysis. In this study, the material model of the concrete and steel for a truss element was defined as the stress-strain relationship to reflect the inelastic behavior of the coupled wall system, as shown in Figure 9.

As shown in Figure 10, the prototype model of the coupled wall system (models A, B) is selected for the inelastic analysis. Model $\mathrm{A}$ is a representative model for the typical design result of the coupled wall system under elastic analysis. In this case, a high reinforcement ratio value is assumed for the wall with an additional axial tensile load $\left(\rho_{f}=0.015\right)$, and a low reinforcement ratio value is assumed for the wall with an additional axial compressive load 


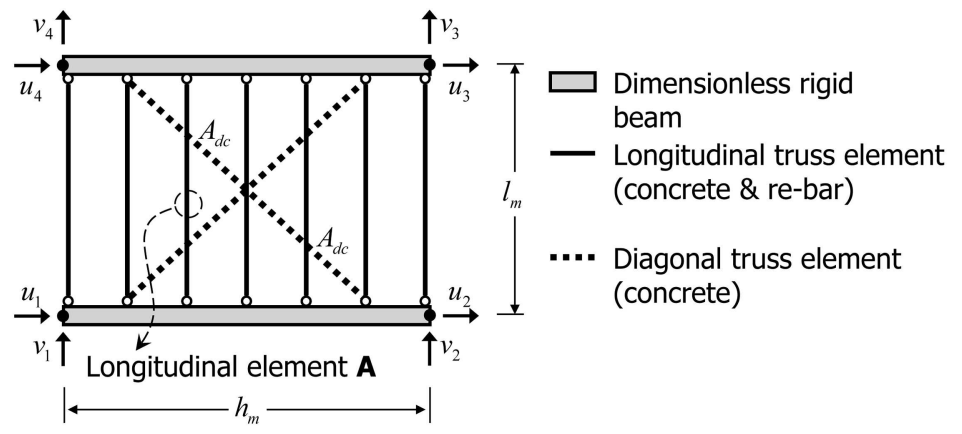

(a) Longitudinal-and-Diagonal-Line-Element-Model (LDLEM) element

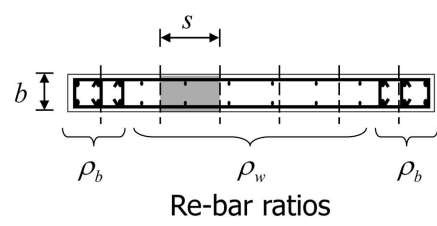

Tributary areas of longitudinal concrete and re-bar elements $\mathbf{A}$

$$
A_{l s}=\rho_{w} b s \quad A_{l c}=b s-A_{l s}
$$

(b) Tributary areas of concrete and re-bar of each longitudinal uniaxial element

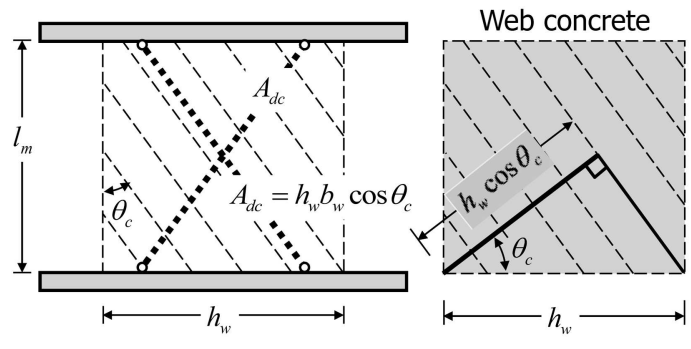

Single set of X-type diagonal concrete struts

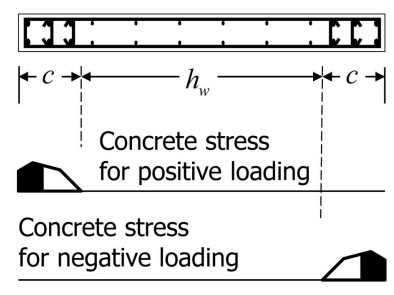

Definition of web depth $h_{w}$

(c) Diagonal concrete strut of wall web concrete

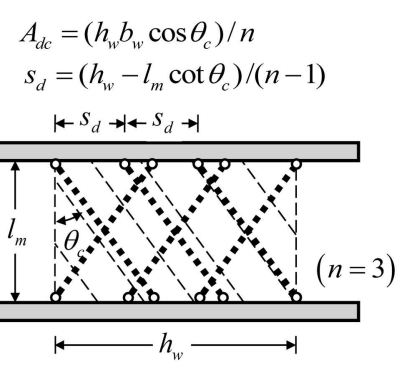

(d) Multiple sets of X-type diagonal concrete struts

Figure 8. Longitudinal-and-Diagonal-Line-Element-Model (LDLEM) for the simulation of the actual behavior of a coupled wall system [17].

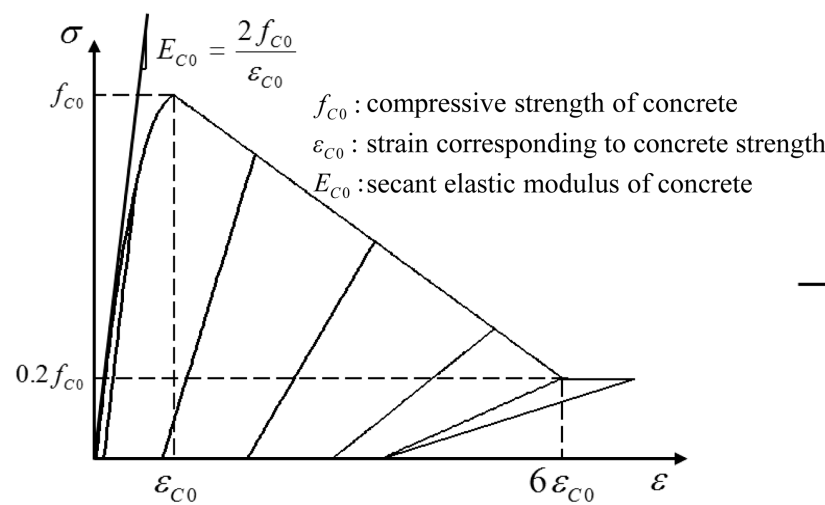

(a)

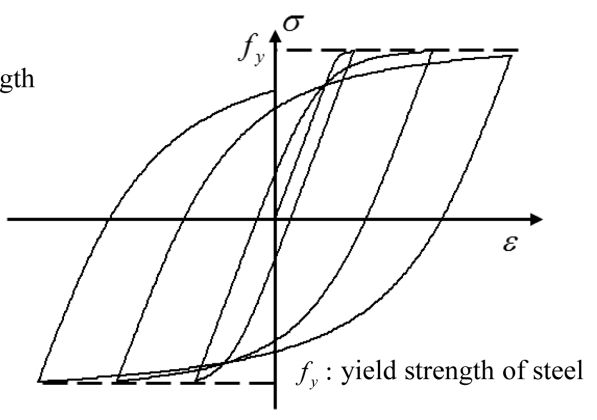

(b)

Figure 9. Material models for concrete and reinforcement: (a) Stress-strain relation for concrete [20], and (b) stress-strain relation for concrete [21].

$\left(\rho_{f}=0.005\right)$. On the other hand, in the case of model $\mathrm{B}$, the reinforcement ratio of the coupled wall is unified as $\rho_{f}=0.01$, and this reinforcement ratio is determined by equalizing the sum of the individual moment strengths of model B to that of model A $\left(M_{1}^{\prime}+\right.$ $M_{2}^{\prime}($ model B $)=M_{1}+M_{2}($ model A $)$, see Figure 10$)$. Except for the reinforcement ratio of the coupled walls, the other design parameters of models A and B are the same.

The LDLEM analysis for models $\mathrm{A}$ and $\mathrm{B}$ in Figure 10 was conducted by using OpenSEES program (PEER 2001 [22]). Static pushover analysis was performed by displacement control. The coupling beams in models $\mathrm{A}$ and $\mathrm{B}$ were modelled with equivalent beam elements (nonlinear beam-column element of OpenSEES (PEER 2001) with fiber section). Moreover, concrete elements resisted only compressive force, whose structural behavior was determined by material model in Figure 9(a).

By using the LDLEM method that simulated the ultimate behavior of the coupled wall system (models A and B), the relationship of the total moment capacity at the base with the drift at the roof was investigated, as shown in Figure 11. According to Figure 11, models A and B show almost the same behavior under a lateral load. The structural performances (stiff- 


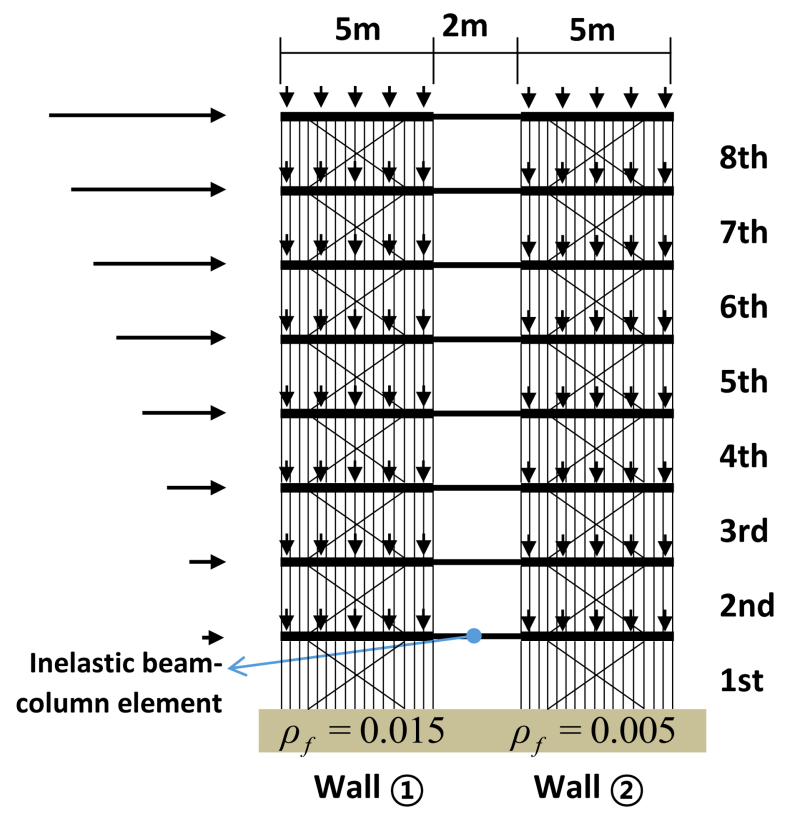

$f^{\prime} c=30 \mathrm{MPa}, f y=400 \mathrm{MPa}$, Story height $=3.1 \mathrm{~m}$, Wall thickness $=0.3 \mathrm{~m}$

Beam width-depth $=0.3 \mathrm{~m}-0.5 \mathrm{~m}$, Flexural reinforcement ratio of beam $=1 \%$

Constant axial load at the base $=0.2 A g f^{\prime} c$
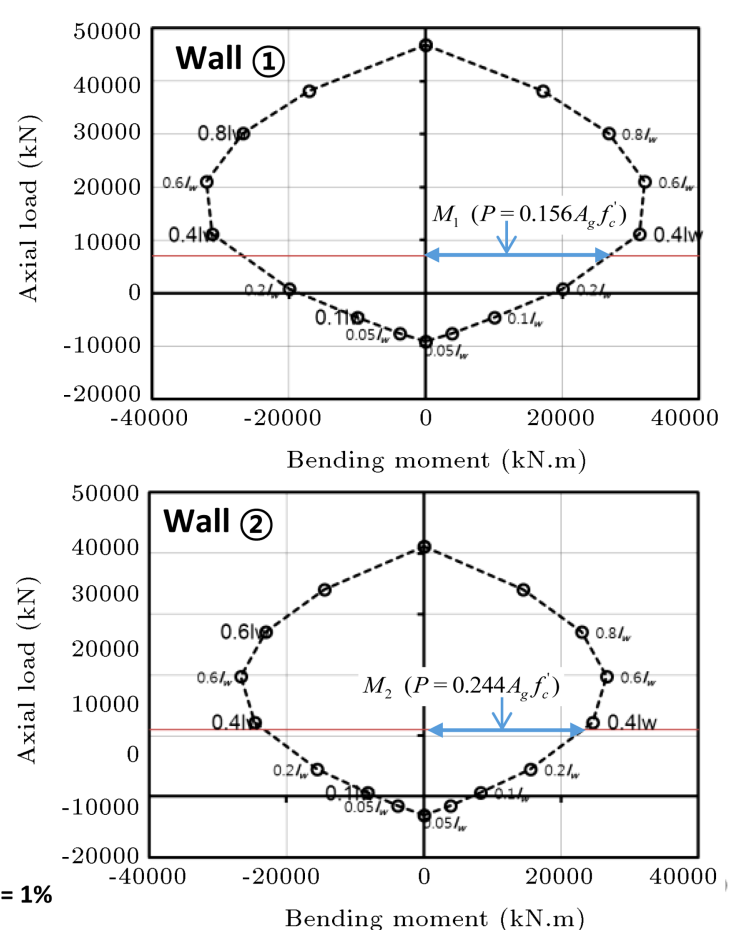

(a) Coupled wall model A ( $\rho_{f}=0.015$ (tension wall), $\rho_{f}=0.005$ (compression wall))
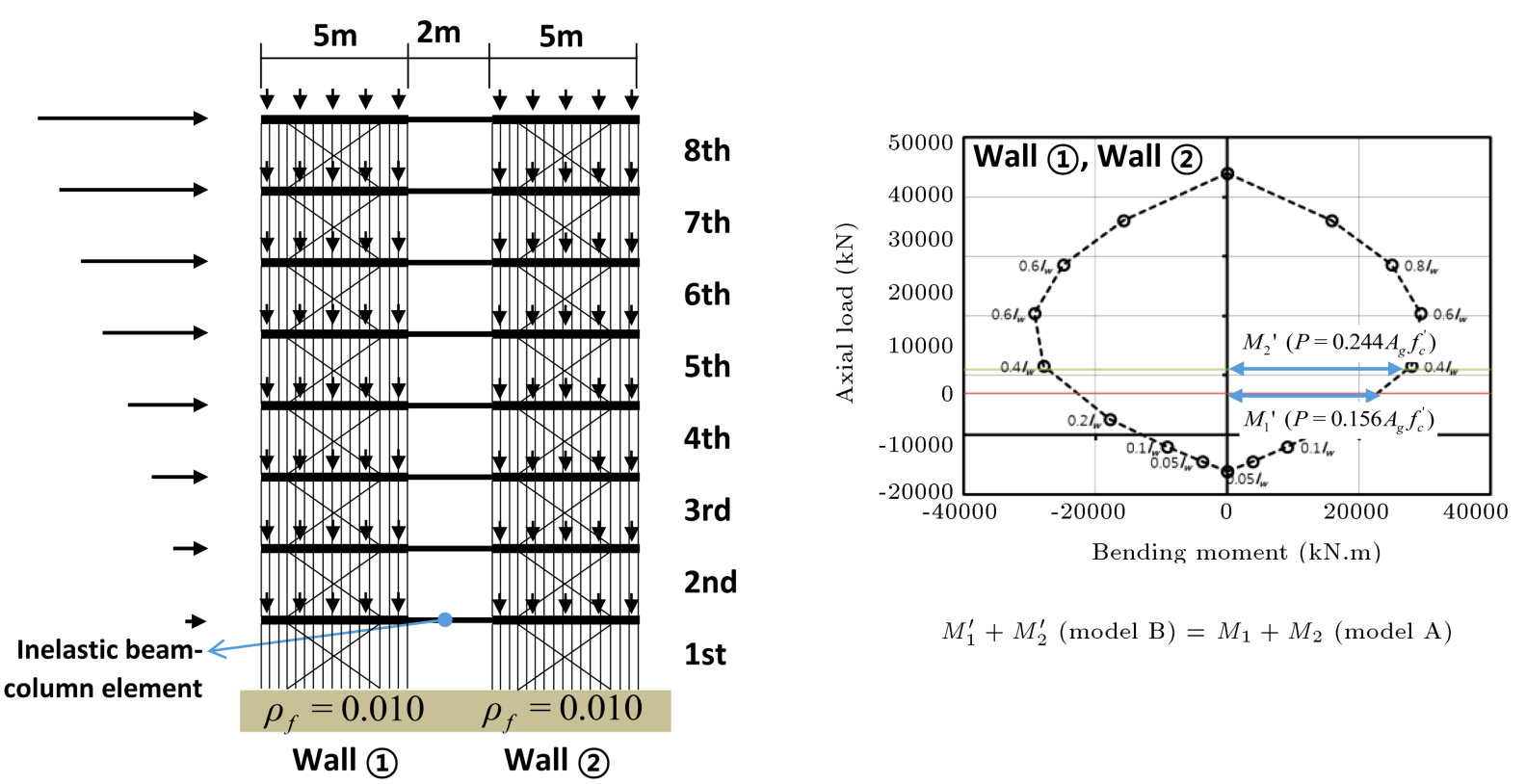

$M_{1}^{\prime}+M_{2}^{\prime}(\operatorname{model} \mathrm{B})=M_{1}+M_{2}(\operatorname{model} \mathrm{A})$

(b) Coupled wall model B ( $\rho_{f}=0.010$ (tension wall), $\rho_{f}=0.010$ (compression wall))

Figure 10. Coupled wall model for inelastic analysis.

ness, strength, and deformability) of the coupled wall systems before/after the moment redistribution are almost identical. Therefore, the moment redistribution concept $[1,14,16]$ for the effective design of the coupled fin walls in high-rise buildings was verified through LDLEM analysis method. Particularly, the high reinforcement ratio of the walls with an additional axial tensile load can reduce when the moment redistribution concept is used as Paulay and Priestley proposed [1]. If the structural design was conducted according to elastic analysis, the flexural reinforcement might be placed such as the pattern of Model A, where the amount of flexural reinforcement in tension-side wall is larger than that of Model B. If lateral load in the opposite direction is applied, the existing compressionside wall will become tension-side wall and the amount 


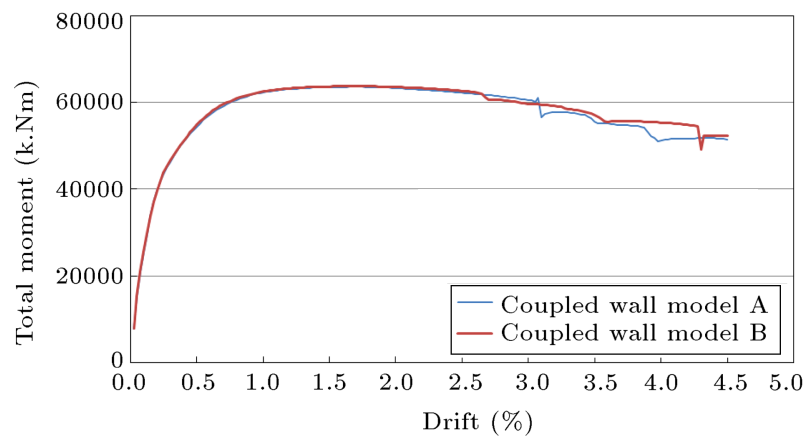

Figure 11. Result of inelastic analysis

of flexural reinforcement will increase. As a result, in the structural design based on the elastic analysis, the amount of the flexural reinforcement is determined by the amount of the flexural reinforcement of the tension-side wall. In addition, according to the result of the analysis of model $\mathrm{B}$, the design made by the elastic analysis has a greater flexural performance than the flexural performance required for the design load. These design results decrease economic feasibility and constructability. Moreover, excessive flexural performance of high-rise RC structural walls may lead to their unexpected brittle shear failure. Therefore, to assure structural safety and economic feasibility, the use of moment redistribution method should be considered seriously. However, further studies are still required to verify the moment redistribution concept under various design parameters and identify the limitations of this method.

\section{Conclusions}

In high-rise buildings, RC structural walls frequently resist lateral loads, such as wind and seismic loads since they have large stiffness and strength. In the high-rise RC building structures, in many cases, the structural RC walls are located on another line and apart from each other, and are designed generally as independent single walls (isolated walls) regardless of their structural behavior. In particular, behavior and design of fin walls at the periphery of strong core wall structure in high-rise buildings were not analyzed seriously despite their structural importance. Sometimes, these RC fin walls, which extend from the center to the boundary of the plan, have a large reinforcement ratio that is more than $1 \%$. Such a value cannot assure economic feasibility and constructability. In the present study, the current design process of these fin walls was investigated, and inelastic analysis and literature review were performed to study the actual behavior of these RC fin walls and to recommend the alternative design method for them. According to the investigation of the current design and elicited results, the walls, located far apart from each other and connected by center walls and beams on another line, were coupled by the beams. Therefore, owing to the large deformation of the coupling beams under the lateral load, large shear forces occurred in coupling beams that were subsequently transferred to the coupled walls as an axial load. Moreover, in the case of high-rise buildings, the number of coupling beams is very large and the axial load that is transferred to the coupled walls is also large. These additional axial forces result in significant reinforcement of the coupled walls. However, the additional axial load from the coupling beam, calculated using the current elastic analysis, is larger since the strength of the coupling beam is limited by the actual detail of the beams. Accordingly, the high-rise RC fin walls, which are located far apart from each other and are connected by center walls and beams on another line, should be designed as a coupled wall system instead of isolated walls.

In the present study, the moment redistribution method was introduced as an alternative design method for high-rise RC fin wall system through a literature review, and it was verified by the inelastic analysis using the LDLEM method, which is a newlydeveloped and specialized structural analysis method for RC wall systems. According to the results of the inelastic analysis and the literature review, the moment redistribution concept can be used for the effective design of the RC fin walls in high-rise buildings. Particularly, by using the moment redistribution concept, the high reinforcement ratio of the walls with the additional axial tensile load can be reduced and the unexpected shear failure of high-rise RC structural systems can be prevented by protecting their excessive flexural performance. However, further studies are still required to verify the moment redistribution concept under various design parameters and identify the limitations of this method.

\section{Acknowledgement}

This work was supported by the research grants of the National Research Foundation of Korea (NRF) (No. 2015R1C1A1A01053471 and Code R-2015-00441 [Midcareer Research Program]). The authors are grateful to the authorities for their support.

\section{References}

1. Paulay, T. and Priestley, M.J.N., Seismic Design of Reinforced Concrete and Masonry Buildings, John Wiley \& Sons, New York (1992).

2. Taranath, B.S., Reinforced Concrete Design of Tall Buildings, CRC Press, London (2009).

3. Kaltakci, M.Y., Arslan, M.H., and Yavuz, G. "Effect of internal and external shear wall location on strength- 
ening weak RC frames", Scientia Iranica. Transactions A, Civil Engineering, 17(4), pp. 312-323 (2010).

4. ACI Committee 318., Building Code Requirement for Structural Concrete (ACI 318-14), American Concrete Institute, Farmington Hills, MI (2014).

5. Midasit, http://www.midasit.com.

6. Bourada, M., Kaci, A., Houari, M.S.A., and Tounsi, A. "A new simple shear and normal deformations theory for functionally graded beams", Steel and Composite Structures, 18(2), pp. 409-423 (2015).

7. Tounsi, A., Houari, M.S.A., and Bessaim, A. "A new 3-unknowns non-polynomial plate theory for buckling and vibration of functionally graded sandwich plate", Struct. Eng. Mech., Int. J., 60(4), pp. 547-565 (2016).

8. Hebali, H., Tounsi, A., Houari, M.S.A., Bessaim, A., and Bedia, E.A.A. "New quasi-3D hyperbolic shear deformation theory for the static and free vibration analysis of functionally graded plates", ASCE J. Engineering Mechanics, 140(2), pp. 374-383 (2014).

9. Bennoun, M., Houari, M.S.A., and Tounsi, A. "A novel five variable refined plate theory for vibration analysis of functionally graded sandwich plates", Mechanics of Advanced Materials and Structures, 23(4), pp. 423-431 (2016).

10. Ait Yahia, S., Ait Atmane, H., Houari, M.S.A., and Tounsi, A. "Wave propagation in functionally graded plates with porosities using various higher-order shear deformation plate theories", Structural Engineering and Mechanics, 53(6), pp. 1143-1165 (2015).

11. Belabed, Z., Houari, M.S.A., Tounsi, A., Mahmoud, S.R., and Anwar Bég, O. "An efficient and simple higher order shear and normal deformation theory for functionally graded material (FGM) plates", Composites: Part B, 60, pp. 274-283 (2014).

12. Houari, M.S.A., Tounsi, A., Bessaim, A., and Mahmoud, S.R. "A new simple three-unknown sinusoidal shear deformation theory for functionally graded plates", Steel and Composite Structures, 22(2), pp. 257-276 (2016).

13. Mahi, A., Adda Bedia, E.A., and Tounsi, A. "A new hyperbolic shear deformation theory for bending and free vibration analysis of isotropic, functionally graded, sandwich and laminated composite plates", Applied Mathematical Modelling, 39, pp. 2489-2508 (2015).

14. Paulay, T. "Seismic design in reinforced concrete-the state of the art in New Zealand", Proceeding of 9th World Conference on Earthquake Engineering, Tokyo, Japan (1988).

15. Paulay, T. " The philosophy and application of capacity design" Scientia Iranica, 2(2), pp. 117-143 (1995).

16. Santhakumar, A.R. "The ductility of coupled shear wall", PhD Thesis, University of Canterbury, Chrischurch, New Zealand (1974).

17. Kim, D.K., Eom, T.S., Lim, Y.J., Lee, H.S., and Park,
H.G. "Macro model for nonlinear analysis of reinforced concrete walls", Journal of the Korea Concrete Institute, 23(5), pp. 569-579 (in Korean) (2011).

18. Park, H.G. and Eom, T.S. "Truss model for nonlinear analysis of RC members subject to cyclic loading", Journal of Structural Engineering, 133(10), pp. 13511363 (2007).

19. Vecchio, F.J. and Collins, M.P. "The modified compression-field theory for reinforced concrete elements subjected to shear", ACI Structural Journal, 83(22), pp. 219-231 (1986).

20. Kent, D.C. and Park, R. "Flexural- members with confined concrete", Proceeding, ASCE, 97(ST7), pp. 1969-1990 (1971).

21. Menegotto, M. and Pinto, P.E. "Method of analysis for cyclically loaded reinforced concrete plane frames including changes in geometry and non-elastic behavior of elements under combined normal force and bending", Proc., IABSE Symp. of Resistance and Ultimate Deformability of Structures Acted on by WellDefined Repeated Loads, IABSE, Libson, Portugal, 13, pp. 15-22 (1973).

22. Pacific Earthquake Engineering Research Center (PEER), Open System for Earthquake Engineering Simulation, Berkeley, CA: University of California at Berkeley (2001).

\section{Biographies}

Tae-Sung Eom is an Associate Professor at the Department of Architectural Engineering in Dankook University in South Korea. He received his BE, MS, and PhD degrees in Architectural Engineering from Seoul National University. His research interests include nonlinear analysis and seismic design of RC structures.

Su-Min Kang is an Associate Professor at the Department of Architectural Engineering in Chungbuk National University in South Korea. He received his BE, MS, and PhD in Architectural Engineering from Seoul National University. His research interests include earthquake design of reinforced concrete structures.

Seung-Yoon $\mathbf{Y u}$ is a Graduate Student at Department of Architectural Engineering in Chungbuk National University in South Korea. He received his BE in Architectural Engineering from Chungbuk National University. His research interests include earthquake design of reinforced concrete structural walls.

Jae-Yo Kim is a Professor at the Department of Architectural Engineering in Kwangwoon University in South Korea. He received his BE, MS, and PhD in Architectural Engineering from Seoul National University. 
His research interests include inelastic FE analysis of reinforced concrete structures and serviceability of $\mathrm{RC}$ flat-plate system.

Dong Kwan Kim is an Assistant Professor at the Department of Architectural Engineering in Cheongju
University in South Korea. He received his BE, $\mathrm{MS}$, and $\mathrm{PhD}$ in Architectural Engineering from Seoul National University. His research interests include earthquake design of reinforced concrete structures and seismic wave generation for earthquake design. 